\title{
FAKTOR RISIKO ERGONOMI DENGAN TERJADINYA KELUHAN MUSCULOSKELETAL DISORDERS PADA PEKERJA OVERHAUL
}

\section{THE RISK OF ERGONOMIC'S FACTOR WITH MUSCULOSKELETAL DISORDERS OF OVERHAUL WORKERS}

\author{
Iin Viradiani \\ PT. Supra Surya Indonesia \\ E-mail: iinvidi.iv@gmail.com
}

\begin{abstract}
PT. PJB UPHT is a company that runs a service in maintaining a unit of power station. The job description includes overhaul that is done manually by its workers. This work that is done manually has a risk of suffering musculoskeletal. The aim of this study is to examine the relation between the risk of ergonomic's factor with musculoskeletal disorders on overhaul workers in mechanical turbine department. This study is an observational descriptive research. The tool used to measure musculoskeletal disorders was Nordic Body Map (NBM) checklist sheet. In order to measure the work postures of workers, REBA (Rapid Entire Body Assessment) method was employed. Meanwhile, questionnaires were used to know types of work. The total population of this research was 17 workers in mechanical turbine. The data was analyzed using cross tabulation to see the relation strength. The result of this study shows that all overhaul workers in mechanical turbine suffer from musculoskeletal. It can be concluded that the risk of ergonomic's factor in this case is type of work have strong relation to the suffering of musculoskeletal on workers.
\end{abstract}

Keywords: mechanical turbine workers, musculoskeletal disorders, the risk of ergonomic's factor

\begin{abstract}
ABSTRAK
PT. PJB UPHT merupakan perusahaan yang bergerak di bidang pemeliharaan unit pembangkit. Pekerjaan yang dilakukan berupa overhaul yang dilakukan secara manual oleh pekerjanya. Pekerjaan yang dilakukan secara manual berisiko terhadap keluhan musculoskeletal. Tujuan dari penelitian ini untuk mengetahui faktor risiko ergonomi dengan terjadinya keluhan musculoskeletal pada pekerja overhaul di bagian mekanik turbin. Penelitian ini merupakan penelitian observational deskriptif. Alat yang digunakan untuk mengukur keluhan musculoskeletal adalah lembar checklist Nordic Body Map (NBM) sedangkan untuk mengukur sikap kerja menggunakan metode penilaian Rapid Entire Body Assessment (REBA), untuk mengetahui jenis pekerjaan menggunakan kuesioner. Jumlah populasi pada penelitian ini sebesar 17 pekerja di bagian mekanik turbin. Analisis data pada penelitian ini menggunakan cross tabulation untuk mengetahui kuat hubungan. Hasil penelitian ini menunjukkan seluruh pekerja overhaul di bagian mekanik turbin memiliki keluhan musculoskeletal. Kesimpulan pada penelitian ini faktor risiko ergonomi yaitu jenis pekerjaan memiliki hubungan yang kuat dengan terjadinya keluhan musculoskeletal pada pekerja.
\end{abstract}

Kata kunci: faktor risiko ergonomi, keluhan musculoskeletal, pekerja mekanik turbin

\section{PENDAHULUAN}

Listrik merupakan kebutuhan masyarakat sehari-hari. Perusahaan listrik menjadi perusahaan yang harus menjaga kinerjanya agar mampu melayani kebutuhan masyarakat selaku konsumen dengan baik. PT. PJB merupakan perusahaan yang bergerak di bidang pembangkitan listrik, untuk menjaga mesin produksi agar kinerjanya optimal maka dilakukan pemeliharaan mesin secara rutin oleh perusahaan. Pemeliharaan atau maintenance pada mesin pembangkit listrik PT. PJB dikelola oleh PT. PJB UPHT.

PT. PJB UPHT merupakan perusahaan yang bergerak di bidang pemeliharaan unit pembangkitan yang terdiri dari operational dan maintenance. PT. PJB UPHT bertugas untuk menunjang kesiapan unit pembangkit dan mendukung kehandalan unit pembangkit dalam beroperasi.

Tuntutan kerja yang tinggi dan pekerjaan yang dilakukan secara manual dapat menyebabkan 
ketidakseimbangan atau gangguan ergonomi pada pekerja. Ergonomi adalah ilmu, seni dan penerapan teknologi yang menyelaraskan antara manusia dalam melakukan aktivitasnya dengan alat atau teknologi yang digunakan untuk mendapatkan kinerja yang optimal (Tarwaka, dkk, 2004). Salah satu masalah yang ada di perusahaan adalah ergonomi, hal ini dikarenakan tidak mudah untuk menyerasikan antara pekerja dengan pekerjaannya.

Pekerja merupakan aset suatu perusahaan. Perusahaan sebaiknya memberikan perlindungan kepada tenaga kerjanya, baik dari segi kenyamanan, keamanan, keselamatan dan kesehatan kerja. perlindungan terhadap tenaga kerja dapat dilakukan dari berbagai aspek termasuk aspek ergonomi. Perlindungan secara ergonomi kepada pekerja dapat dilakukan dengan cara menyesuaikan antara pekerja dengan jenis pekerjaannya. Jenis pekerjaan yang tidak sesuai dengan kemampuan pekerja dapat menyebabkan munculnya keluhan yang dapat menyebabkan gangguan kesehatan. Pekerja yang memiliki beban kerja tinggi dan melakukan pekerjaan secara manual seringkali mengalami keluhan musculoskeletal.

Keluhan musculoskeletal merupakan keluhan atau gangguan yang dirasakan pada bagian otot skeletal, keluhan dapat berupa rasa sakit atau nyeri secara ringan hingga rasa sakit yang berat. Otot skeletal meliputi otot leher, otot bahu, otot lengan, otot tangan, jari, otot punggung, otot pinggang dan otot bagian bawah (Tarwaka, dkk, 2004).

Beberapa kasus yang dilaporkan terkait keluhan pada pekerja antara lain hasil studi Departemen Kesehatan pada tahun 2005 yang dilaporkan dalam profil masalah kesehatan di Indonesia diketahui sebesar $40,5 \%$ pekerja mengalami penyakit yang berhubungan dengan jenis pekerjaannya. Sebanyak 9.482 pekerja yang berada di 12 kabupaten atau kota mengalami gangguan kesehatan sebagai berikut $16 \%$ mengalami keluhan musculoskeletal, 8\% mengalami gangguan kardiovaskuler, 5\% mengalami gangguan syaraf, 3\% mengalami gangguan pernafasan dan 1,5\% mengalami gangguan telinga hidung tenggorokan atau THT (Sumiati, 2007).

Menurut International Labour Organization (ILO) terjadi lebih dari 250 juta kecelakaan kerja dan lebih dari 160 pekerja yang sakit akibat pekerjaannya setiap tahunnya. Berdasarkan data pekerja yang sakit akibat pekerjaannya, sekitar 32\% menunjukkan hasil cedera musculoskeletal yang diakibatkan aktivitas otot yang berlebihan.
ILO dalam program The Prevention of Occupational Disease menyatakan bahwa di 27 negara di bagian Uni Eropa, gangguan kesehatan yang dialami pekerja yang paling umum diderita adalah musculoskselal disorders (MSDs). Salah satu masalah musculoskeletal yang dialami ialah carpal tunnel syndrome, sebanyak 59\% pekerja mengalami keluhan ini dari total penyakit yang diakui oleh Badan Statistik Penyakit Akibat Kerja di Eropa pada tahun 2005.

WHO (2009) melaporkan bahwa dari seluruh kasus kecacatan, 10\% diakibatkan oleh musculoskeletal disorders. Keluhan musculoskeletal di Korea mengalami peningkatan dari 1.634 kasus yang terjadi pada tahun 2001 menjadi 5.502 kasus pada tahun 2010. Sejalan dengan Eropa, Inggris juga mengalami kenaikan keluhan pada pekerja dengan keluhan musculoskeletal mengalami peningkatan sebesar 40\% pada periode 2011 hingga 2012 (ILO, 2013).

Penelitian di Amerika pada tahun 2004 menyatakan bahwa sebanyak $60 \%$ pekerja manual handling mengalami cidera pada punggung yang diakibatkan oleh aktivitas otot yang berlebihan (Munir, 2012). Aktivitas otot yang berlebihan meliputi kegiatan mengangkat, menarik serta memegang alat.

Penelitian Astuti (2009) pada industri tekstil di Indonesia menyatakan bahwa pekerja memiliki keluhan musculoskeletal. Keluhan musculoskeletal

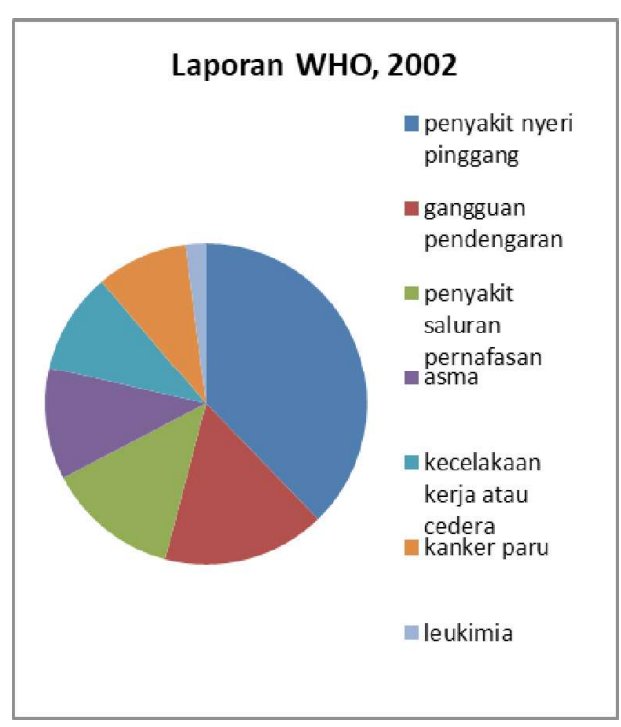

Gambar 1. Laporan WHO tentang Faktor Risiko Angka Kesakitan dan Kematian Tahun 2002. 
pada tubuh bagian atas dirasakan sebanyak $65 \%$ pekerja dari $52.4 \%$ pekerja yang mengalami keluhan musculoskeletal. Pada penelitian ini menyatakan bagian tubuh pekerja yang mengalami keluhan musculoskeletal antara lain pinggang $(82,5 \%)$, pantat $(60 \%)$, leher bawah $(47,5 \%)$, leher atas $(45 \%)$ dan bahu (45\%). Keluhan ini diakibatkan oleh sikap kerja yang dominan dengan posisi menunduk dalam waktu yang relatif lama. Menurut Wiyatno (2011) sikap kerja yang statis dan berulang dalam waktu yang relatif lama berisiko terhadap keluhan musculoskeletal disorders (MSDs).

Pekerjaan merupakan salah satu faktor yang berpengaruh terhadap terjadinya keluhan pada kesehatan. Pekerjaan yang dilakukan secara manual merupakan pekerjaan yang berpotensi dan lebih berisiko terhadap keluhan musculoskeletal. Sebagian besar perusahaan di Indonesia masih melakukan proses produksi secara manual karena keterbatasan mesin atau alat.

Jenis pekerjaan berpengaruh secara langsung terhadap sikap kerja. Sikap kerja yang tidak ergonomi berisiko terhadap terjadinya keluhan musculoskeletal pada pekerja. Sikap kerja mempengaruhi kinerja otot, otot yang menerima beban di luar kemampuannya, maupun beban statis secara berulang-ulang dapat merusak sendi, ligamen dan tendon (Tarwaka, dkk, 2004).

Kekuatan fisik pekerja berhubungan dengan kesegaran tubuhnya. Hasil laporan NIOSH (Tarwaka, 2010) menyatakan bahwa pekerja yang kesegaran tubuhnya rendah lebih berisiko terhadap keluhan pada otot dibandingkan dengan pekerja yang tingkat kesegaran tubuhnya tinggi.

PT. PJB UPHT bergerak di bidang penyedia jasa pemeliharaan dan perawatan mesin pembangkit atau biasa disebut overhaul. Overhaul merupakan kegiatan yang aktivitas pekerjaannya dilakukan secara manual oleh para pekerjanya. Para pekerja overhaul di bagian mekanik turbin merupakan pekerja dengan risiko keluhan musculoskeletal paling tinggi. Hal ini dikarenakan pekerja overhaul di bagian mekanik turbin menggunakan alat dengan beban alat yang berat.

Pekerja overhaul di bagian mekanik turbin memiliki jenis pekerjaan yang berbeda, terdiri dari 3 (tiga) jenis pekerjaan yaitu bagian pembongkaran baut, bagian pemanasan baut dan bagian palumemalu. Baut pada mesin turbin yang harus dilepas pekerja memiliki berat antara 1 (satu) sampai 5

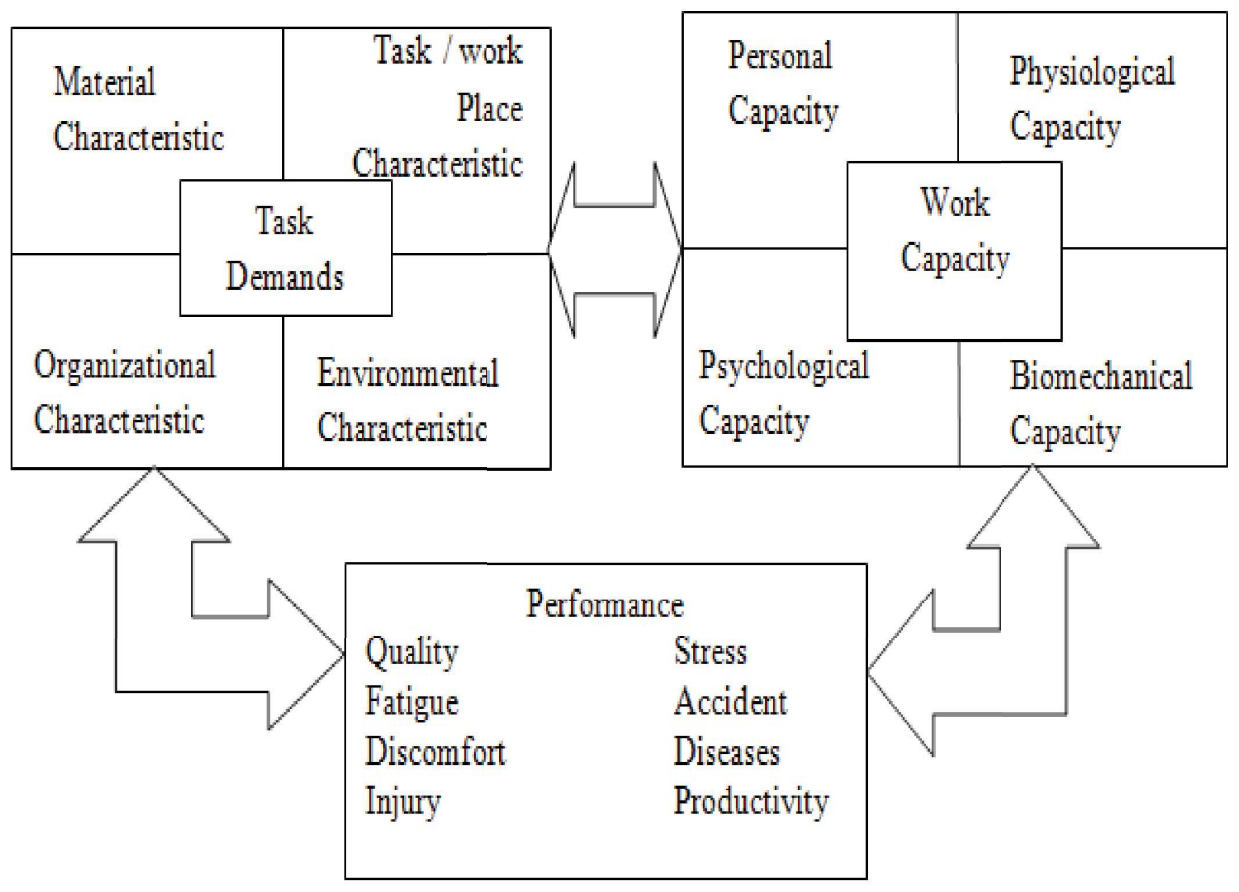

Sumber: Manuaba, 2000

Gambar 2. Konsep Dasar dalam Ergonomi 
(lima) kg bahkan lebih dan palu yang digunakan untuk memalu baut memiliki berat hingga $10 \mathrm{~kg}$.

Hasil wawancara terkait pekerja overhaul kepada officer K3 PT. PJB UPHT selaku pengawas pekerjaan menyatakan bahwa pekerja overhaul berpotensi terhadap keluhan pada otot terutama pekerja di bagian mekanik turbin. Hal ini didukung dengan adanya keluhan berupa nyeri atau rasa sakit yang dirasakan pekerja selama overhaul berlangsung. Tujuan dari penelitian ini adalah untuk mengetahui faktor risiko ergonomi yang terdiri dari jenis pekerjaan dan sikap kerja dengan terjadinya keluhan musculoskeletal pada pekerja overhaul di bagian mekanik turbin.

\section{METODE}

Penelitian ini adalah penelitian observasional dengan analisa data bersifat deskriptif untuk menggambarkan suatu keadaan secara objektif dan mendeskripsikan sejumlah variabel yang berhubungan dengan akibat.

Penelitian dilakukan di PT. PJB UPHT Gresik. Waktu pengumpulan data dilaksanakan pada Mei 2017. Data primer didapatkan dengan observasi, penyebaran kuesioner dan wawancara, sedangkan data sekunder didapatkan dari studi dokumen dan profil perusahaan PT PJB UPHT Gresik. Responden dalam penelitian ini adalah seluruh pekerja overhaul di bagian mekanik turbin sebesar 17 pekerja.

Variabel dependen dalam penelitian ini adalah keluhan musculoskeletal yang dinilai menggunakan checklist penilaian Nordic Body Map (NBM). Variabel independen dalam penelitian ini adalah faktor risiko ergonomi yang terdiri dari jenis pekerjaan dan sikap kerja. Jenis pekerjaan ditanyakan menggunakan kuesioner sedangkan sikap kerja penilaiannya dilakukan dengan observasi. Observasi dilakukan dengan mengamati sikap kerja pekerja dari ujung kepala hingga ujung kaki selama bekerja oleh peneliti dan dinilai menggunakan pengukuran sikap kerja Rapid Entire Body Assessment (REBA). Metode REBA adalah suatu cara untuk menganalisis sikap kerja pekerja yang sensitif dengan adanya perubahan pada posisi kerja (Tarwaka, 2010).

Data hasil penelitian yang telah diperoleh di lapangan akan dikumpulkan dan diolah untuk mengetahui kuat hubungan antara variabel menggunakan cross tabulation dan untuk mengukur tingkat hubungan menggunakan nilai korelasi. Hasil analisis data disajikan dalam bentuk narasi.

\section{HASIL}

\section{Faktor Risiko Ergonomi}

\section{Jenis Pekerjaan}

Pengumpulan data terkait jenis pekerjaan pada metode ini dilakukan dengan wawancara menggunakan kuesioner. Berdasarkan hasil kuesioner diketahui terdapat 3 (tiga) jenis pekerjaan yang dilakukan pekerja overhaul di bagian mekanik turbin yaitu pemanasan baut, palu-memalu dan bagian pembongkaran baut. Berdasarkan Tabel 1 dapat diketahui bahwa dari seluruh pekerja di bagian mekanik turbin sebesar 17 pekerja, 8 pekerja $(47,8 \%)$ bekerja di bagian pembongkaran baut.

\section{Sikap Kerja}

Penilaian sikap kerja pada pekerja overhaul di bagian mekanik turbin dilakukan dengan cara observasi dan mendokumentasikan sikap kerja pekerja selama bekerja baik dengan video maupun dengan gambar, kemudian sikap kerja diukur menggunakan metode Rapid Entire Body Assessment (REBA).

Berdasarkan metode REBA, sikap kerja dikategorikan menjadi 5 (lima) risiko yaitu: risiko sangat rendah, risiko rendah, risiko sedang, risiko tinggi dan risiko sangat tinggi. Data sikap kerja yang telah diukur menggunakan metode REBA menunjukkan hasil bahwa pekerja di bagian mekanik turbin memiliki risiko tingkat sedang dan tingkat tinggi.

Berdasarkan tabel 2 dapat diketahui bahwa sebanyak 10 pekerja (58.8\%) dari total 17 pekerja di bagian mekanik turbin memiliki sikap kerja dengan risiko sedang.

Tabel 1. Distribusi Responden Berdasarkan Jenis Pekerjaannya di Bagian Mekanik Turbin, Mei 2017

\begin{tabular}{lcc}
\hline \multicolumn{1}{c}{ Jenis Pekerjaan } & Frekuensi & Persentase (\%) \\
\hline Pemanasan Baut & 2 & 11,8 \\
Palu-memalu & 7 & 41,2 \\
Pembongkaran Baut & 8 & 47,1 \\
\hline Total & 17 & 100,0 \\
\hline
\end{tabular}




\section{Keluhan Musculoskeletal}

Data terkait keluhan musculoskeletal pada pekerja didapat melalui wawancara menggunakan lembar penilaian NBM (Nordic Body Map). Penilaian ini dimaksudkan untuk mengetahui keluhan atau rasa sakit yang dirasakan pekerja pada bagian otot tubuhnya. Berdasarkan metode NBM keluhan pada otot dikategorikan menjadi 4 (empat) yaitu kategori rendah, kategori sedang, kategori tinggi dan kategori sangat tinggi. Berdasarkan data yang diperoleh dapat diketahui bahwa pekerja di bagian mekanik turbin memiliki keluhan musculoskeletal tingkat sedang hingga tinggi. Distribusi pekerja di bagian mekanik tubin berdasarkan keluhan musculoskeletal yang dirasakan terdapat pada Tabel 3. Berdasarkan Tabel 3 sebanyak 14 pekerja $(82,4 \%)$ dari total 17 pekerja di bagian mekanik turbin memiliki keluhan musculoskeletal tingkat sedang.

\section{Hubungan Faktor Risiko dengan Terjadinya Keluhan Musculoskeletal}

\section{Hubungan Jenis Pekerjaan dengan Keluhan Musculoskeletal}

Berdasarkan hasil analisis yang menggunakan cross tabulation untuk mengetahui kuat hubungan antara jenis pekerjaan dengan keluhan musculoskeletal maka didapatkan hasil seperti pada

Tabel 2. Distribusi Responden Berdasarkan Sikap Kerja pekerja di Bagian Mekanik Turbin, Mei 2017

\begin{tabular}{lcc}
\hline \multicolumn{1}{c}{$\begin{array}{c}\text { Risiko Sikap } \\
\text { Kerja }\end{array}$} & Frekuensi & Persentase (\%) \\
\hline Sedang & 10 & 58,8 \\
Tinggi & 7 & 41,2 \\
\hline Total & 17 & 100,0 \\
\hline
\end{tabular}

Tabel 4. Berdasarkan tabel 4 dapat diketahui bahwa dari total 17 pekerja, sebanyak 3 pekerja $(17,6 \%)$ mengalami keluhan musculoskeletal tingkat tinggi yang merupakan pekerja mekanik turbin di bagian palu-memalu.

Berdasarkan hasil uji statistik menggunakan cross tabulation untuk mengetahui kuat hubungan antar variabel dengan ukuran tabel $>2 \times 2$ menggunakan Cramer's V. Berdasarkan hasil uji diketahui nilai Cramer's V sebesar 0,553, hal tersebut menunjukkan korelasi yang kuat karena semakin mendekati angka 1 , sehingga terdapat hubungan yang kuat antara jenis pekerjaan dengan terjadinya keluhan musculoskeletal pada pekerja overhaul di bagian mekanik turbin.

\section{Hubungan Sikap Kerja dengan Keluhan Musculoskeletal}

Berdasarkan hasil analisis menggunakan cross tabulation untuk mengetahui kuat hubungan antara sikap kerja pekerja overhaul di bagian mekanik turbin dengan keluhan musculoskeletal maka didapatkan hasil seperti pada Tabel 5. Berdasarkan Tabel 5 dapat diketahui bahwa dari total 17 pekerja, sebanyak 3 pekerja $(17,6 \%)$ mengalami keluhan musculoskeletal tingkat tinggi yang memiliki sikap kerja dengan risiko sedang 1 pekerja $(10 \%)$ dan memiliki sikap kerja berisiko tinggi sebanyak 2 pekerja $(28,6 \%)$.

Tabel 3. Distribusi Responden Berdasarkan Keluhan Musculoskeletal Pada Pekerja di Bagian Mekanik Turbin, Mei 2017

\begin{tabular}{lcc}
\hline Keluhan MSDs & Frekuensi & Persentase (\%) \\
\hline Sedang & 14 & 82,4 \\
Tinggi & 3 & 17,6 \\
\hline Total & 17 & 100,0 \\
\hline
\end{tabular}

Tabel 4. Hubungan Jenis Pekerjaan dengan Keluhan Musculoskeletal pada Pekerja di Bagian Mekanik Turbin

\begin{tabular}{lcccccc}
\hline \multirow{2}{*}{\multicolumn{1}{c}{ Jenis Pekerjaan }} & \multicolumn{4}{c}{ Tingkat Keluhan MSDs } & \multirow{2}{*}{ Cramer's V } \\
\cline { 2 - 5 } & \multicolumn{2}{c}{ Sedang } & \multicolumn{2}{c}{ Tinggi } & \\
\cline { 2 - 5 } & $\mathbf{n}$ & $\mathbf{\%}$ & $\mathbf{n}$ & $\mathbf{\%}$ & \\
\hline Pemanasan baut & 2 & 100 & 0 & 0 & 0,553 \\
Palu-memalu & 4 & 57,1 & 3 & 42,9 & Hubungan Kuat \\
Pembongkaran baut & 8 & 100 & 0 & 0 & \\
\hline Total & $\mathbf{1 4}$ & $\mathbf{8 2 , 4}$ & $\mathbf{3}$ & $\mathbf{1 7 , 6}$ & \\
\hline
\end{tabular}


Berdasarkan hasil uji statistik menggunakan cross tabulation untuk mengetahui kuat hubungan antar variabel dengan ukuran tabel $2 \times 2$ menggunakan contingency coefficient. Berdasarkan hasil uji diketahui nilai contingency coefficient sebesar 0,233 , hal tersebut menunjukkan korelasi yang lemah karena semakin mendekati angka 0 , maka dapat disimpulkan bawa terdapat hubungan yang lemah antara sikap kerja dengan terjadinya keluhan musculoskeletal pada pekerja overhaul di bagian mekanik turbin.

\section{PEMBAHASAN}

\section{Faktor Risiko Ergonomi dan Terjadinya Keluhan Musculoskeletal pada Pekerja Overhaul di Bagian Mekanik Turbin}

Overhaul merupakan produk utama PT. PJB UPHT. Fokus daripada pekerjaan overhaul adalah perawatan, perbaikan dan pemeliharaan pada mesin pembangkit. Tujuan daripada overhaul adalah untuk mengoptimalkan kinerja mesin pada saat beroperasi. Kegiatan ini berupaya untuk memperbaiki atau mengubah kondisi mesin menjadi lebih baik walaupun tidak dapat mengembalikan kondisi mesin seperti semula.

Kegiatan overhaul merupakan kegiatan dari manajemen outage yang dilakukan oleh PT. PJB, yang mana manajemen outage merupakan kegiatan yang mengurusi seluruh pekerjaan yang berhubungan dengan unit pembangkit pada listrik. Pekerjaan overhaul pada pelaksanaannya dipimpin oleh manajer teknik yang bertanggung jawab secara penuh. Manajer teknik membawahi manajer proyek yang bertugas mengawasi keberlangsungan kegiatan overhaul. Pada pelaksanaannya, apabila dibutuhkan tenaga tambahan untuk overhaul maka PT. PJB UPHT merekrut tenaga outsourcing yang berasal dari PT Mitra Karya Prima (MKP). Perusahaan MKP merupakan perusahaan yang menyediakan jasa pekerja overhaul di PT. PJB UPHT, sehingga dapat dikatakan bahwa overhaul pada pelaksanaannya merupakan hasil kerja sama antara PT. PJB UPHT selaku pemilik proyek atau kegiatan dengan PT. MKP selaku penyedia jasa pekerja overhaul.

Berdasarkan hasil uji statistik untuk mengetahui kuat hubungan antara jenis pekerjaan dan sikap kerja terhadap terjadinya keluhan musculoskeletal pada pekerja overhaul di bagian mekanik turbin, terdapat 2 (dua) kategori hubungan yaitu hubungan kuat dan hubungan lemah. Hubungan yang kuat yaitu antara jenis pekerjaan dengan terjadinya keluhan musculoskeletal sedangkan hubungan yang lemah yaitu sikap kerja dengan terjadinya keluhan musculoskeletal pada pekerja.

Berdasarkan tabel 3, pekerja overhaul di bagian mekanik turbin adalah pekerja yang memiliki risiko terhadap terjadinya keluhan musculoskeletal, karena pada penelitian ini semua pekerja mengalami keluhan musculoskeletal mulai dari keluhan tingkat sedang hingga keluhan tingkat tinggi yang dialami oleh 3 pekerja dari total 17 pekerja. Keluhan ini dapat disebabkan oleh aktivitas otot yang berlebihan sehingga mempengaruhi kekuatan otot dan mengganggu kinerja otot. Tingkat kesegaran tubuh yang rendah berisiko terkena keluhan atau rasa nyeri pada otot. Keluhan otot seringkali dirasakan oleh pekerja yang jenis pekerjaannya memerlukan kekuatan otot yang tinggi hal ini dikarenakan keluhan otot meningkat seiring dengan bertambahnya aktivitas fisik pekerja.

Berdasarkan hasil observasi yang dilakukan peneliti, pekerja overhaul di bagian mekanik turbin rata-rata memiliki tubuh yang bugar dengan otot yang relatif besar, sehingga dapat dikatakan bahwa pekerja di bagian mekanik turbin merupakan pekerja yang kuat. Pekerja di bagian mekanik turbin juga mampu mengangkat beban alat yang mencapai $10 \mathrm{~kg}$.

Kebijakan perusahaan PT. PJB UPHT terkait kesegaran jasmani pekerjanya meliputi: perusahaan

Tabel 5. Hubungan Sikap Kerja dengan Keluhan Musculoskeletal pada Pekerja di Bagian Mekanik Turbin

\begin{tabular}{lccccc}
\hline \multirow{2}{*}{ Risiko Sikap Kerja } & \multicolumn{3}{c}{ Tingkat Keluhan MSDs } & \\
\cline { 2 - 5 } & $\mathbf{n}$ & $\mathbf{0}$ & $\mathbf{n}$ & $\mathbf{\%}$ & Contingency Coefficient \\
\cline { 2 - 5 } & 9 & 90 & 1 & 10 & \\
\hline Sedang & 5 & 71,4 & 2 & 28,6 & 0,233 \\
Tinggi & $\mathbf{1 4}$ & $\mathbf{8 2 , 4}$ & $\mathbf{3}$ & $\mathbf{1 7 , 6}$ & Hubungan Lemah \\
\hline Total & & & & \\
\hline
\end{tabular}


membatasi akses keluar-masuk kendaraan sehingga pekerja harus berjalan kaki ke area setiap pagi. Hal ini tanpa disadari pekerja bahwa sebenarnya mereka telah memiliki kebiasaan berolahraga secara rutin, selain itu dengan berjalan setiap hari dapat meningkatkan kelancaran aliran darah dalam tubuh sehingga tubuh menjadi sehat. Kebijakan lain yang diterapkan oleh PT. PJB UPHT adalah terkait gizi pekerja. Kebijakan berupa penyediaan air minum pada pekerja agar pekerja terhindar dari dehidrasi serta pemberian makanan tambahan pada pekerja atau yang biasa disebut "extrafooding", pemberian makanan tambahan pada pekerja dilakukan pada jam coffebreak. Hal inilah yang menjadikan pekerja overhaul di bagian mekanik turbin merupakan pekerja yang memiliki kesegaran tubuh yang baik.

Pekerjaan overhaul merupakan pekerjaan yang berhubungan dengan perawatan, perbaikan dan pemeliharaan mesin dengan tujuan untuk mengoptimalkan kinerja mesin. Pelaksanaan overhaul di PT. PJB UPHT di bagian Gas Turbin (GT) dibagi menjadi beberapa jenis antara lain Major Inspection (MI), Turbin Inspection (TI), dan Combustion Inspection (CI).

Pekerja overhaul di bagian mekanik turbin adalah pekerja yang melakukan pembongkaran pada mesin turbin. Pembongkaran ini dilakukan untuk membersihkan bagian dalam mesin atau mengganti komponen yang ada pada mesin. Pembongkaran mesin turbin dilakukan sesuai dengan prosedur yang sudah ditetapkan oleh perusahaan.

Pekerja di bagian mekanik turbin bekerja secara manual menggunakan alat yang memiliki beban berkapasitas tinggi, selain itu area kerja yang terbatas juga menyebabkan keterbatasan gerak pada pekerja sehingga berpengaruh terhadap munculnya sikap kerja yang tidak ergonomi. Penelitian yang dilakukan kepada pekerja overhaul di bagian mekanik turbin menunjukkan hasil bahwa sebanyak 17 pekerja mengalami keluhan musculoskeletal tingkat sedang hingga tinggi. Keluhan musculoskeletal dapat terjadi akibat sikap kerja yang salah.

Sikap kerja yang salah dan menyebabkan ketidakseimbangan pada tubuh berpengaruh terhadap timbulnya musculoskeletal disorders (Tarwaka, 2004). Penyebab munculnya musculoskeletal disorders antara lain beban statis yang diterima otot, pembebanan berlebih pada otot serta gerakan yang dilakukan secara berulang-ulang dalam waktu yang relatif lama. Musculoskeletal disorders menyebabkan kerusakan pada sendi, ligamen, serta tendon (Tarwaka, dkk, 2004).

Pekerja overhaul di bagian mekanik turbin memiliki berdasarkan sikap kerjanya memiliki risiko sedang hingga tinggi. Pekerjaan di bagian mekanik turbin terdiri dari 3 (tiga) bagian yaitu bagian pemanasan baut, bagian palu-memalu dan bagian pembongkaran baut. Jenis pekerjaan pada pekerja overhaul di bagian mekanik turbin berkaitan secara langsung terhadap sikap kerja pekerja.

Pada tahap awal, yang dilakukan adalah melakukan pemanasan pada baut. Pada tahap ini baut yang ada pada mesin turbin dipanaskan menggunakan alat yang disebut "bolt heater, pemanasan dilakukan agar baut mengalami penyusutan sehingga mempermudah pada tahap pembongkaran. Proses pemanasan pada baut dilakukan selama 5 (lima) menit atau lebih.

Pekerja di bagian pemanasan baut memiliki sikap kerja yang dominan statis, pekerja di bagian pemanasan baut bekerja dengan posisi leher menunduk, punggung membungkuk dan lengan yang menjauhi tubuh. Posisi kaki pekerja di bagian pemanasan berbeda-beda bergantung pada area baut yang dipanasi. Pekerja yang memanasi baut di bagian samping mesin turbin cenderung berada pada posisi duduk sehingga kedua kaki ditumpukan pada mesin dan tumpuan berat tubuh tidak berada pada kaki, sedangkan pekerja yang memanasi baut di bagian atas mesin turbin posisi kaki cenderung ditekuk atau jongkok dan tumpuan berat badan pada tubuh berada pada kaki.

Pekerja di bagian pemanasan baut mengalami keluhan musculoskeletal tingkat sedang, hal ini dikarenakan pekerja di bagian pemanasan baut melakukan aktivitas yang berulang dengan otot cenderung statis. Otot yang statis dalam waktu yang relatif lama dapat menyebabkan kontraksi pada otot jika dibiarkan tanpa adanya relaksasi. Kontraksi otot secara terus menurus menyebabkan rasa kaku dan pegal pada otot, semakin lama dan tinggi kontraksi pada otot berisiko terhadap penumpukan asam laktat. Penumpukan asam laktat yang tinggi dapat menyebabkan terhambatnya aliran atau suplai oksigen ke otot, otot yang tidak menerima aliran atau suplai oksigen dapat berakibat terjadinya kejang pada otot (Ulfah, dkk, 2014). 
Tahapan selanjutnya setelah pemanasan baut adalah proses palu-memalu. Proses ini dilakukan oleh pekerja mekanik turbin di bagian palu-memalu. Pada proses ini bagian yang dipalu adalah "drat" atau ulir pada baut. Proses ini dilakukan agar baut bisa dibuka. Pekerja di bagian ini menggunakan palu dengan berat palu yang digunakan mencapai $10 \mathrm{~kg}$ bahkan lebih. Semakin berat palu yang digunakan maka semakin cepat pula "drat" pada baut terbuka dan baut dapat dilepas.

Jenis pekerjaan pada pekerja overhaul di bagian mekanik turbin berkaitan langsung dengan sikap kerja pekerja dalam melakukan pekerjaannya. Pekerja di bagian palu-memalu memiliki sikap kerja yang dominan pada posisi badan membungkuk dengan tumpuan keseimbangan tubuh pada kaki. Lengan pekerja di bagian palu-memalu membutuhkan kekuatan otot yang besar karena pekerja di bagian ini memalu menggunakan alat yang memiliki berat atau kapasitas tinggi.

Pekerja overhaul di bagian mekanik turbin dengan jenis pekerjaan palu-memalu merupakan pekerja dengan keluhan musculoskeletal tingkat sedang hingga tinggi. Hal ini dikarenakan pekerja di bagian ini bekerja dengan alat yang memiliki beban tinggi atau berat sehingga otot mengalami peregangan saat bekerja. Otot yang mengalami peregangan antara lain otot tulang belakang diakibatkan pada saat memalu posisi cenderung membungkuk dan otot lengan dikarenakan kekuatan yang digunakan berada pada lengan atas. Aktivitas otot yang berlebihan dapat menyebabkan terjadinya musculoskeletal disorders (Tarwaka, 2010).

Tahapan selanjutnya adalah tahap pembongkaran baut, pekerja overhaul di bagian mekanik turbin pada bagian ini melakukan pelepasan baut yang menempel pada mesin dengan memutar baut keluar dari tempatnya. Pekerja di bagian ini harus melakukan aktivitas berulang pada otot yaitu gerakan memutar dan menahan beban baut yang diputar. Pelepasan baut dilakukan secara manual oleh pekerja.

Pekerja di bagian pembongkaran baut memiliki sikap kerja dominan punggung membungkuk, leher menunduk dan lengan memuntir. Posisi kaki pekerja saat bekerja bergantung pada lokasi baut yang dibongkar atau dilepas. Apabila lokasi baut yang dilepas berada di bagian atas mesin turbin maka posisi kaki pekerja adalah jongkok sehingga tumpuan berat tubuh berada pada kaki. Lokasi baut di bagian samping mesin turbin maka posisi pekerja adalah duduk dengan kedua kaki ditumpukan pada mesin sehingga beban tubuh tidak ditopang oleh kaki.

Berdasarkan 3 (tiga) jenis pekerjaan yang dilakukan oleh pekerja di bagian mekanik turbin, sikap kerja yang paling dominan adalah bagian batang tubuh membungkuk, dalam posisi membungkuk otot pada bagian punggung bekerja lebih keras untuk menahan beban tubuh. Beban kerja yang berat juga menyebabkan peregangan pada otot akibat menahan beban alat utamanya pada bagian palu-memalu. Area kerja yang terbatas juga menyebabkan terhambatnya ruang gerak pekerja sehingga sikap kerja pekerja tidak ergonomi karena menahan keseimbangan tubuh. Hal inilah yang menyebabkan terjadinya keluhan musculoskeletal pada pekerja di bagian mekanik turbin terutama di bagian pinggang dan bahu.

Pekerjaan di bagian mekanik turbin juga merupakan pekerjaan yang cenderung statis. Pekerjaan yang dilakukan secara statis membuat otot berkontraksi sehingga muncul rasa kaku dan pegal pada otot. Menurut Ulfah, dkk (2014) semakin lama kontraksi pada otot berisiko pada penimbunan asam laktat. Penumpukan asam laktat menyebabkan terhambatnya suplai oksigen, hal ini dapat menyebabkan kejang pada otot.

Berdasarkan statistik penelitian ini menunjukkan hubungan yang lemah antara sikap kerja dengan terjadinya keluhan musculoskeletal dan hubungan yang kuat antara jenis pekerjaan dengan keluhan musculoskeletal. Jenis pekerjaan mempengaruhi sikap kerja sedangkan sikap kerja berpengaruh langsung terhadap pergerakan otot yang dapat memicu keluhan musculoskeletal.

Kebijakan perusahaan dalam hal ini sangat membantu pekerja dalam meminimalisir risiko keluhan musculoskeletal. Pekerja di bagian mekanik turbin merupakan pekerja dengan beban kerja tinggi, utamanya di bagian palu-memalu dan pembongkaran baut. Tim dibentuk yang tiap timnya beranggotakan minimal 2 hingga 4 anggota, dengan adanya tim pekerja diharapkan tidak memfosir tenaganya namun bekerja sesuai kemampuannya. Hal ini yang diterapkan oleh pekerja di bagian palu-memalu. Pekerjaan di bagian pelepasan baut, pekerja tidak ditarget harus melepas berapa baut untuk tiap 
orang. Pekerja hanya dituntut untuk menyelesaikan pekerjaan secara tepat waktu, adapun apabila pekerjaan overhaul harus diselesaikan dalam waktu singkat maka perusahaan akan menambah jumlah tenaga kerja dan menerapkan sistem shift.

Menurut Tarwaka (2010) seiring berjalannya waktu baik umur pekerja maupun masa kerja pekerja, keluhan musculoskeletal yang dirasakan akan semakin meningkat. Hal tersebut dikarenakan kekuatan otot seseorang akan mengalami penurunan dan mengalami degenerasi. Pernyataan beberapa pekerja overhaul di bagian mekanik turbin bahwasanya semakin lama bekerja di bagian mekanik turbin maka otot semakin kuat dan beban kerja yang berat tidak terasa, mereka mengatakan bahwa awal bekerja merupakan masa yang berat untuk menyesuaikan jenis pekerjaan yang menggunakan alat (baik palu maupun baut) yang memiliki beban hingga mencapai $10 \mathrm{~kg}$ bahkan lebih, namun seiring waktu dan semakin lama bekerja beban alat dirasa tidak lagi berat karena pekerja sudah terbiasa.

Hasil penelitian menunjukkan sikap kerja yang berisiko sedang hingga tinggi sehingga harus diupayakan tindakan perbaikan terkait sikap kerja pekerja. Hasil penelitian juga menunjukkan adanya keluhan musculoskeletal pada pekerja overhaul di bagian mekanik turbin dengan tingkat keluhan sedang hingga tinggi, sehingga perlu diwaspadai untuk tindakan treatmentnya.

Penelitian ini menunjukkan adanya keluhan musculoskeletal pada pekerja overhaul di bagian mekanik turbin. Hasil ini berbanding lurus dengan tingkat risiko ergonomi dengan risiko musculoskeletal pada pekerja. Penelitian ini menunjukkan beberapa faktor yang saling terkait yang menyebabkan keluhan musculoskeletal pada pekerja. Faktor individu berupa kesegaran tubuh menunjang dalam meminimalisir tingkat keluhan musculoskeletal pada pekerja. Faktor risiko yang paling berpengaruh adalah jenis pekerjaan. Pekerjaan yang dilakukan secara manual menggunakan alat yang memiliki beban berkapasitas tinggi serta dalam pekerjaannya membutuhkan kekuatan otot yang tinggi, berpotensi terhadap keluhan musculoskeletal padan pekerja.

\section{SIMPULAN}

Kesimpulan penelitian ini bahwa pekerja overhaul di bagian mekanik turbin mengalami keluhan musculoskeletal tingkat sedang hingga tinggi. Pada penelitian ini jenis pekerjaan mempengaruhi sikap kerja, sedangkan berdasarkan statistik jenis pekerjaan berhubungan kuat dengan terjadinya keluhan musculoskeletal pada pekerja. Jenis pekerjaan paling berpengaruh terhadap keluhan musculoskeletal yang dirasakan pekerja adalah di bagian palu-memalu. Hasil penelitian ini menunjukkan sikap kerja pekerja di bagian mekanik turbin berisiko sedang hingga tinggi. Walaupun sikap kerja memiliki hubungan yang lemah dengan keluhan musculoseletal, bekerja dengan risiko ergonomi tinggi dapat menyebabkan pekerja mengalami keluhan musculoskeletal yang tinggi, sehingga keluhan musculoskeletal pada pekerja harus diperhatikan.

\section{DAFTAR PUSTAKA}

Astuti, S., 2009. Gambaran Faktor Risiko Pekerjaan dan Keluhan Gejala Musculoskeletal Disorders (MSDs) pada Tubuh Bagian Atas Pekerja di Sektor Informal Butik Lamode Depok Lama. Skripsi. Depok: Fakultas Kesehatan Masyarakat Universitas Indonesia.

International Labour Organization (ILO)., 2013. The Prevention of Occupational Disease. Geneva. www.ilo.org/.../wcms_208226.pdf. Diakses pada Juni 2017

International Labour Organization (ILO)., 2013. Keselamatan dan Kesehatan Kerja di Tempat Kerja. Jakarta: International Labour Office.

Munir, S., 2012. Analisis Nyeri Punggung Bawah pada Pekerja Bagian Final Packing dan Part Supplu di PT. X Tahun 2012. Tesis. Depok: Fakultas Kesehatan Masyarakat Universitas Indonesia.

NIOSH., 2007. Ergonomic Guidelines for Manual Material Handling. 4676 Columbia Parkway Cincimati. Diakses 8 November 2016 dalam http://www.cdc.gov. 
Tarwaka, Bakri, Solichul HA., dan Sudiajeng, L., 2004. Ergonomi untuk Keselamatan, Kesehatan Kerja, dan Produktivitas. Surakarta. Harapan Press.

Tarwaka., 2010. Ergonomi Industri Dasar-Dasar Pengetahuan Ergonomi dan Aplikasi di Tempat Kerja. Solo: Harapan Press.

Ulfah, N., Harwanti, S., Nurcahyo, P., 2014. Sikap Kerja dan Risiko Musculoskeletal Disorders pada
Pekerja Laundry. Jurnal Kesehatan Masyarakat Nasional. Vol. 8, No. 7.

Wiyatno, T., 2011. Hubungan Antara Beban Kerja dan Sikap Kerja dengan Keluhan Musculoskeletal pada Buruh Panggul di Kawasan Industri Canti Kota Semarang. Skripsi. Semarang: Fakultas Ilmu Keolahragaan. Universitas Negeri Semarang.

WHO. 2000. Guidelines for Controlling and Monitoring the Tobacco Epidemic. Geneva: World Health Organization. 